\title{
Câncer de pele: a importância do seu diagnóstico, tratamento e prevenção
}

\author{
Skin cancer: the importance of diagnosis, treatment and prevention \\ Cancer de piel: la importancia de su diagnóstico, tratamiento y prevención
}

Beatrix Sabóia Zink*

\begin{abstract}
Resumo
O câncer de pele é a doença mais comum em caucasianos em todo o mundo. O câncer de pele não melanoma (CPNM) é responsável por mais de $90 \%$ de todos os cânceres de pele. Dados referem que a incidência de CPNM está aumentando a cada ano, especialmente entre os jovens. O carcinoma de células escamosas representa $25 \%$ de todos os CPNM, enquanto o carcinoma basocelular é mais frequentemente diagnosticado, correspondendo a 70\% dos casos, podendo chegar a afetar mais de um milhão de pessoas a cada ano. Essas estimativas estão aumentando em todo o mundo, e no Brasil não é diferente. Apenas para este ano, estimou-se cerca de 200.000 novos casos de CPNM, detectando na população um aumento de $88 \%$ no risco de desenvolvimento de CPNM após quatro anos. Por isso, os médicos devem estar atentos para identificar uma lesão de CPNM e tratá-la corretamente, a fim de evitar a recorrência e a persistência do tumor. Considerando que cada lesão de CPNM é única e o seu tratamento deve ser direcionado para cada tipo de paciente, técnicas cirúrgicas e não cirúrgicas estão sendo desenvolvidas para alcançar a remissão completa do tumor, preservando o tecido normal, a função da área comprometida e para atingir um melhor resultado estético. Portanto, aprender sobre o desenvolvimento CPNM, bem como seu diagnóstico e tratamento, pode impactar nas medidas de saúde pública e contribuir para a prevenção de novos casos.
\end{abstract}

Descritores: Neoplasias cutâneas; Carcinoma basocelular; Carcinoma de células escamosas.

\begin{abstract}
Skin cancer is the most common disease in Caucasians all over the world. The non-melanoma skin cancer (NMSC) is responsible for more than $90 \%$ of all skin cancer. Data presents that the incidence of NMSC is currently increasing each year, especially among young people. The squamous cell carcinoma represents $25 \%$ of all NMSC, and the basal cell carcinoma is the most common diagnostic, accounting for $70 \%$ of the cases, and may affect more than 1 million people every year. These estimates are increasing worldwide, and in Brazil this is not different. Only for this year, there's an estimate of almost 200.000 new cases of NMSC, detecting an increase of $88 \%$ in the risk of developing NMSC after four years. Therefore, the physicians must be alert to identify a lesion of NMSC and to treat it correctly in order to avoid recurrence and persistence of the tumor. Considering that each NMSC lesion is one of a kind and its treatment must be directed to each patient, surgical and non-surgical techniques are being developed to reach the complete remission of the tumor, preserving the normal tissue, the function of the area affected by the tumor and to achieve a better aesthetic outcome. Therefore, learning about the NMSC development, diagnostic and treatment could impact the health system and contribute to prevent new cases.
\end{abstract}

Keywords: Skin neoplasms; Carcinoma, basal cell; Carcinoma, squamous cell.

\section{Resumen}

El cancer de piel es la enfermedad más común en caucásicos, en todo el mundo. El cancer de piel no melanoma (CPNM) es responsable por más del $90 \%$ de todos los canceres de piel. Los datos refieren que la incidencia de CPNM está aumentando cada año, especialmente entre los jóvenes. El carcinoma de células escamosas representa el 25\% de todos los CPNM, mientras que el carcinoma basocelular es más frecuentemente diagnosticado, correspondiendo al 70\% de los casos, pudiendo llegar a afectar a más de un millón de personas cada año. Estas 
estimaciones están aumentando en todo el mundo, y Brasil no es un caso apartado. Solo para este año, se estimó cerca de 200.000 nuevos casos de CNPM, detectándose en la población un aumento del $88 \%$ en el riesgo de desarrollar CPNM después de cuatro años. Por eso, los médicos deben estar atentos para identificar una lesión de NMSC y tratarla correctamente, a fin de evitar la recurrencia y la persistencia del tumor. Considerando que cada lesión de CPNM es única, y que su tratamiento debe ser direccionado para cada tipo de paciente, las técnicas quirúrgicas y no quirúrgicas están siendo desarrolladas para alcanzar la remisión completa del tumor, preservando el tejido normal y la función del área comprometida, y para conseguir un mejor resultado estético. Por lo tanto, aprender sobre el desarrollo del CPNM, así como su diagnóstico y tratamiento, puede impactar en las medidas de salud pública y contribuir para la prevención de nuevos casos.

Palabras clave: Neoplasias cutáneas; Carcinoma basocelular; Carcinoma de células escamosas.

\section{O câncer de pele e sua importância}

Atualmente, dados mostram o câncer de pele como a doença mais comum no mundo entre os caucasianos, sendo o tipo não melanoma o mais frequentemente encontrado., $\mathrm{O}$ câncer de pele não melanoma (CPNM) corresponde a $90 \%$ de todos os cânceres de pele, e sua incidência tem aumentado principalmente numa faixa etária cada vez mais jovem. ${ }^{1,2}$ Por isso, a prevenção, o diagnóstico inicial e o tratamento têm um substancial significado na saúde pública e grande impacto nas políticas governamentais.

O câncer de pele acomete mais as populações de pele clara, do fototipo que queima e não bronzeia e, por isso, hispânicos, asiáticos e negros desenvolvem em menor número esse tipo de câncer.' Também é encarado como um importante sinal de alerta, pois sabe-se que, uma vez que o paciente apresente uma lesão de CPNM, há uma chance maior de aparecimento de um novo câncer de pele. ${ }^{2}$ Alguns estudos revelam que a história pessoal de câncer de pele do tipo não melanoma aumenta em $35 \%$ o risco de desenvolvimento de outro câncer do mesmo tipo, em três anos, e $50 \%$ em cinco anos após o diagnóstico inicial. ${ }^{2}$ Dessa forma, os indivíduos que já apresentaram alguma lesão de CPNM devem ser acompanhados regularmente para que, no caso de apresentarem uma nova lesão, tenham o diagnóstico precoce e o tratamento mais eficaz.

O CPNM, geralmente tem crescimento lento, é localmente invasivo e raramente resulta em metástase a distância., ${ }^{1,2}$ É, portanto, uma neoplasia de bom prognóstico, com altas taxas de cura se for tratado de forma adequada e oportuna. Contudo, em alguns casos em que há demora no diagnóstico ou um tipo histopatológico mais agressivo, esse câncer pode levar a deformidades físicas graves devido à invasão local das células tumorais., ${ }^{1,2}$

\section{Nomenclatura}

Existem dois grupos distintos de câncer da pele: os não melanoma, mais frequentes e menos agressivos, e os melanomas, mais agressivos, porém menos comuns. $\mathrm{O}$ carcinoma basocelular (CBC) e o carcinoma epidermoide (CEC) são geralmente citados na literatura como $\mathrm{CPNM}{ }^{1,2}$

Apesar do termo CPNM ser mais conhecido, Eide e Weinstock defendem a terminologia de ceratocarcinomas para o grupo de CBC e CEC. ${ }^{2}$ Isto porque esta terminologia de CPNM também incluiria outras malignidades cutâneas, como o carcinoma de Merkel e o linfoma cutâneo. ${ }^{2} \mathrm{O}$ problema fundamental do termo CPNM, além da ambiguidade, é que ele define as malignidades mais comuns, o que não é uma verdade, pois deve-se considerar outros cânceres cutâneos. ${ }^{2}$ Todavia, como este é o mais conhecido na literatura científica, ele será utilizado nesse artigo para se referir ao $\mathrm{CBC}$ e ao $\mathrm{CEC}$.

\section{O câncer de pele não melanoma}

Os CPNMs correspondem a tumores de diferentes linhagens. Os mais frequentes são: o CBC, responsável por $70 \%$ dos diagnósticos, e o CEC, que representa $25 \%$ dos casos. ${ }^{1,2}$ Ambos apresentam altos percentuais de cura se forem detectados precocemente, e apenas uma pequena proporção se torna letal, visto que o número de óbitos resultante é muito baixo.,2 Assim, entre os tumores de pele, são os cânceres de maior incidência e mais baixa mortalidade. ${ }^{2}$

\section{O carcinoma epidermoide}

O CEC é considerado um tumor maligno derivado dos ceratinócitos. O maior fator de risco para o seu desenvolvimento é a exposição crônica e excessiva ao sol; por isso, ocorre geralmente em 
áreas fotoexpostas. 1 Também há estudos relacionando o CEC com a presença do papillomavírus humano (HPV) e com a imunossupressão.,2

A taxa de cura do CEC pode chegar a $95 \%$ quando detectado e tratado precocemente. No entanto, o poder de invasão e destruição tecidual e a chance de metástase desse câncer são maiores quando comparado ao $\mathrm{CBC}{ }^{2}$

A Doença de Bowen (BD) também é descrita como uma apresentação de CEC in situ por se tratar de uma neoplasia dos ceratinócitos de localização exclusivamente intraepidérmica, com comportamento biológico caracteristicamente menos invasivo. ${ }^{1,2}$ É mais comum nas áreas fotoexpostas e tem comportamento menos agressivo quando comparado a áreas não fotoexpostas. $^{2}$

\section{O carcinoma basocelular}

O CBC é um tumor maligno originado de células não queratinizantes que formam a camada basal da epiderme. ${ }^{12}$ É a neoplasia mais comum em humanos e sua origem é multifatorial, apesar de grande parte das lesões estarem relacionadas aos distúrbios com maior sensibilidade à exposição excessiva à radiação ultravioleta (RUV). ${ }^{2}$

O CBC pode ser classificado clinicamente e histopatologicamente em: nodular ou nóduloulcerado, superficial, esclerodermiforme, cístico, metaplásico, adenoide, ceratótico, infundibular, infiltrativo, micronodular e pigmentado. ${ }^{2}$

\section{Análise epidemiológica do câncer de pele não melanoma}

\section{Epidemiologia do câncer de pele não melanoma}

Dados publicados pela Organização Mundial de Saúde (OMS) estimam uma incidência mundial de 2 a 3 milhões de casos de CPNM ao ano. ${ }^{1} \mathrm{Ou}-$ tros estudos nos EUA estimam até 3,5 milhões de casos ao ano só no continente norte-americano. ${ }^{2}$ Ainda, dados alarmantes mostram que, em cada três cânceres diagnosticados no mundo, um é de pele; e, entre os americanos, um em cada cinco indivíduos o desenvolverá ao longo da sua vida. ${ }^{1}$ Mas esses números podem estar subestimados, pois a verdadeira incidência do câncer de pele é difícil de ser avaliada. Isto porque, geralmente, os cânceres de pele não são contados pelos centros de câncer, em função do seu grande número e, na maioria das vezes, por serem diagnosticados nos centros particulares. ${ }^{1}$

Outro aspecto epidemiológico relevante é que a incidência do câncer de pele tem aumentado em todo o mundo e acometido uma faixa etária cada vez mais jovem. ${ }^{1,2}$ A média do aumento de CPNM na população dos EUA, Austrália, Canadá e Europa está estimada entre 3 a $8 \%$ ao ano. ${ }^{2}$ Esse aumento tem influenciado as políticas públicas e afeta as medidas de saúde. Um exemplo disso são os EUA, que têm o câncer de pele ocupando o quinto lugar em gastos em saúde com câncer.' Outro exemplo é a Austrália, conhecida pela maior incidência mundial de câncer de pele, que adotou campanhas públicas educativas de prevenção e passou a não detectar um aumento tão significativo na incidência do CPNM desde o início das campanhas. ${ }^{1}$

Nos EUA, a última estimativa de prevalência do CPNM na população foi de 450 casos por 100 mil habitantes. Aplicando esse índice na atual população americana tem-se uma estimativa de 1,4 milhão de indivíduos com CPNM por ano. ${ }^{2}$

As últimas e únicas estatísticas oficiais relacionadas ao CPNM no Brasil estão disponíveis no portal do Instituto Nacional do Câncer (Inca) por meio da publicação do Estimativa 2014 Incidência de Câncer no Brasil. De acordo com seus dados mais recentes, espera-se um total de 182.130 casos novos de CPNM em 2014, sendo 98.420 casos entre os homens e 83.710 entre as mulheres. Esses valores correspondem a um risco estimado de 100,75 casos novos a cada 100 mil homens e 82,24 a cada 100 mil mulheres. ${ }^{3}$ É importante notar na tabela 1 que o número de casos de CPNM representa um terço de todas as ocorrências de câncer estimadas, e, por isso, este é analisado à parte.

Em 2012, estimou-se que o Brasil atingiria a marca de 134.170 novos casos de CPNM; sendo 62.680 casos novos entre homens e $71.490 \mathrm{em}$ mulheres. ${ }^{4}$ Esses valores corresponderam a um risco estimado de 65 casos novos a cada $100 \mathrm{mil}$ homens e de 71 para cada 100 mil mulheres. ${ }^{4} \mathrm{Na}$ mesma publicação do Inca referente ao ano de 2010, o número de casos novos de CPNM estimados para o Brasil foi de 113.850; sendo 53.410 
entre homens e de 60.440 nas mulheres. ${ }^{5}$ Estes valores corresponderam a um risco estimado de 56 casos novos a cada 100 mil homens e 61 para cada 100 mil mulheres. ${ }^{5}$ Com isso, pôde-se calcular um aumento de 68.280 (59,9\%) novos casos de CPNM no Brasil em quatro anos e um aumento maior que $88 \%$ no risco estimado da população masculina e $36 \%$ da feminina.

No Brasil, conforme demonstrado na tabela 1, o CPNM se configura como no restante do mundo, sendo o grupo de neoplasias mais incidente em ambos os sexos. Também é bastante provável que exista um deficit no registro devido ao subdiagnóstico e subnotificação e, portanto, o próprio Inca recomenda que as estimativas das taxas de incidência e dos números esperados de casos novos em relação a esse tipo de câncer sejam consideradas como mínimas. ${ }^{3}$

$\mathrm{O}$ aspecto positivo em relação à epidemiologia do câncer de pele é que, apesar do aumento da sua incidência, a mortalidade vem diminuindo e, atualmente, a mortalidade para o CPNM é extremamente baixa, com uma taxa de sobrevida acima de cinco anos em 95\% dos casos. ${ }^{1}$ A sociedade americana estima que cerca de 1.000 a 2.000 pessoas morram por CPNM por ano, sendo a sua maioria pacientes idosos, com comorbidades graves, imunossuprimidos e que não receberam tratamento adequado., ${ }^{1,2}$

\section{Epidemiologia do carcinoma basocelular}

Dentre os CPNM, sabe-se, também, que o $\mathrm{CBC}$ é de três a cinco vezes mais comum que o CEC na população caucasiana e que aproximadamente $75 \%$ dos cânceres de pele diagnosticados nos EUA são CBC. No Brasil, calcula-se que o CBC seja responsável por mais de 75\% dos CPNMs. ${ }^{6}$ Já nos EUA, no Canadá, na Austrália e na Europa, a incidência do $\mathrm{CBC}$ tem aumentado cerca de 3 a $6 \%$ ao ano., ${ }^{1,2}$

Tabela 1: Estimativas para o ano de $\mathbf{2 0 1 4}$ das taxas brutas de incidência por 100 mil habitantes e de número de casos novos por câncer, segundo sexo e localização primária.

\begin{tabular}{|c|c|c|c|c|c|c|c|c|}
\hline \multirow{4}{*}{$\begin{array}{l}\text { Localização Primária da } \\
\text { Neoplasia Maligna }\end{array}$} & \multicolumn{8}{|c|}{ Estimativa dos Casos Novos } \\
\hline & \multicolumn{4}{|c|}{ Homens } & \multicolumn{4}{|c|}{ Mulheres } \\
\hline & \multicolumn{2}{|c|}{ Estado } & \multicolumn{2}{|c|}{ Capitais } & \multicolumn{2}{|c|}{ Estado } & \multicolumn{2}{|c|}{ Capitais } \\
\hline & Casos & Taxa Bruta & Casos & Taxa Bruta & Casos & Taxa Bruta & Casos & Taxa Bruta \\
\hline Próstata & 68.800 & 70,42 & 17.540 & 82,93 & - & - & - & - \\
\hline Mama Feminina & - & - & - & - & 57.120 & 56,09 & 19.170 & 80,67 \\
\hline Colo do Útero & - & - & - & - & 15.590 & 15,33 & 4.530 & 19,20 \\
\hline Traqueia, Brônquio e Pulmão & 16.400 & 16,79 & 4.000 & 18,93 & 10.930 & 10,75 & 3.080 & 13,06 \\
\hline Cólon e Reto & 15.070 & 15,44 & 4.860 & 22,91 & 17.530 & 17,24 & 5.650 & 23,82 \\
\hline Estômago & 12.870 & 13,19 & 2.770 & 13,07 & 7.520 & 7,41 & 2.010 & 8,44 \\
\hline Cavidade Oral & 11.280 & 11,54 & 2.220 & 10,40 & 4.010 & 3,92 & 1.050 & 4,32 \\
\hline Laringe & 6.870 & 7,03 & 1.460 & 6,99 & 770 & 0,75 & 370 & 1,26 \\
\hline Bexiga & 6.750 & 6,89 & 1.910 & 8,91 & 2.190 & 2,15 & 730 & 2,97 \\
\hline Esôfago & 8.010 & 8,18 & 1.460 & 6,76 & 2.770 & 2,70 & 540 & 0,00 \\
\hline Ovário & - & - & - & - & 5.680 & 5,58 & 2.270 & 9,62 \\
\hline Linfoma de Hodgkin & 1.300 & 1,28 & 410 & 5,72 & 880 & 0,83 & 420 & 8,64 \\
\hline Linfoma näo Hodgkin & 4.940 & 5,04 & 1.490 & 6,87 & 4.850 & 4,77 & 1.680 & 7,06 \\
\hline Glândula Tireoide & 1.150 & 1,15 & 470 & 1,76 & 8.050 & 7,91 & 2.160 & 9,08 \\
\hline Sistema Nervoso Central & 4.960 & 5,07 & 1.240 & 5,81 & 4.130 & 4,05 & 1.370 & 5,81 \\
\hline Leucemias & 5.050 & 5,20 & 1.250 & 5,78 & 4.320 & 4,24 & 1.250 & 5,15 \\
\hline Corpo do Útero & - & - & - & - & 5.900 & 5,79 & 2.690 & 11,24 \\
\hline Pele Melanoma & 2.960 & 3,03 & 950 & 4,33 & 2.930 & 2,85 & 1.150 & 4,57 \\
\hline Outras Localizaçōes & 37.520 & 38,40 & 9.070 & 42,86 & 35.350 & 34,73 & 8.590 & 36,49 \\
\hline Subtotal & 203.930 & 208,77 & 51.100 & 241,30 & 190.520 & 187,13 & 58.710 & 248,46 \\
\hline Pele não Melanoma & 98.420 & 100,75 & 19.650 & 92,72 & 83.710 & 82,24 & 22.540 & 95,26 \\
\hline Todas as Neoplasias & 302.350 & 309,53 & 70.750 & 334,08 & 274.230 & 269,35 & 81.250 & 343,85 \\
\hline
\end{tabular}

*Números arredondados para 10 ou múltiplos de 10.

Fonte: Estimativa 2014 - Incidência de Câncer no Brasil (Inca). ${ }^{6}$ 
Em uma proporção de 2:1 entre os sexos, dados mundiais referem que homens têm maior ocorrência que mulheres. ${ }^{1,2}$ Nas jovens, há uma elevação em casos do CBC, o que pode estar relacionado ao bronzeamento artificial e às atividades ao ar livre, ${ }^{2}$ segundo estudos recentes. O risco estimado ao longo da vida, nos EUA, é de 33 a 39\%, para homens, e de 23 a 28\% para as mulheres da população caucasiana. ${ }^{2}$ Nos últimos 30 anos, a incidência do CBC foi calculada com um aumento - sendo mais significativo nos homens - entre 20 a $80 \%$ na população norte-americana. ${ }^{2}$

$\mathrm{O}$ CBC comumente atinge a cabeça e o pescoço, em ambos os sexos; no entanto, devido ao aumento da sua incidência, outras áreas do corpo, como braços e tronco, também têm sido mais acometidos. ${ }^{2}$ Dados americanos mostram uma incidência de 70 a $80 \%$ dos casos de CBC na cabeça (mais frequentemente na face) e $25 \%$ no tronco., ${ }^{1,2}$

A morte em decorrência do CBC é rara, mas seu maior risco é a possibilidade de invasão para tecidos e estruturas adjacentes. A estimativa de mortalidade ajustada pela idade é de 0,12 por 100.000 habitantes. ${ }^{2}$ Porém, a sua morbidade é difícil de ser calculada, uma vez que a disfunção e a mutilação gerada pela malignidade e pelo seu tratamento têm importante impacto psicossocial e econômico. ${ }^{1,2}$ A maioria dos relatos tem descrito uma taxa de metástase entre 0,0028 e 0,1\% para o CBC. ${ }^{1}$

Ainda, alguns estudos revelam que a incidência do CBC está em constante crescimento, e o que, antes, em geral, acometia somente a população com idade superior a 50 anos vem afetando jovens em todo o mundo. Por isso, tornou-se assunto de interesse para a saúde pública. Uma prova disso é que, em países como a Austrália - onde há campanhas de saúde e educação para prevenção de câncer de pele -, nas últimas duas décadas, não houve aumento dos casos em adultos jovens. Portanto, o entendimento do CBC quanto a sua epidemiologia, patogenia e tratamento é de fundamental importância social e econômica para a população, em geral, e para a política de saúde pública.

\section{Epidemiologia do carcinoma epidermoide}

A incidência do CEC também tem aumentado nos últimos anos, com uma estimativa de 3-10\% ao ano. Essa incidência é maior em idosos e no sexo masculino, com uma proporção de 3:1. ${ }^{2}$ A maior parte das lesões ocorre em áreas fotoexpostas, como cabeça e pescoço. Apresenta o maior índice de mortalidade por câncer de pele após os 85 anos, responsável por $70 \%$ das mortes por CPNM. ${ }^{2}$

\section{Etiologia}

Autores referem que os principais fatores responsáveis pelo aumento da ocorrência do CPNM seriam o crescimento do buraco na camada de ozônio, o crescimento das práticas de atividades recreativas ao ar livre e mais indivíduos com episódios de queimaduras solares intermitentes na pele. ${ }^{1}$ Em 1991, foi realizada uma estimativa prevendo que em 2050, devido a uma redução de $10 \%$ da camada de ozônio, haverá cerca de 12 milhões de novos casos de câncer de pele só nos EUA, com a morte de 200.000 pessoas. ${ }^{1}$ Dessa forma, espera-se que cada $1 \%$ de redução na camada de ozônio corresponda a um aumento de 2,7\% na incidência do CPNM. ${ }^{1}$

A partir dessa teoria, percebe-se que apenas uma pequena mudança na camada de ozônio pode provocar um grande impacto na incidência do câncer de pele. Portanto, o monitoramento da tendência de aumento nos dados de câncer, a identificação dos fatores de risco e a modificação desses fatores são medidas que certamente causarão impacto nos seus dados epidemiológicos. ${ }^{2}$

\section{Fatores de risco}

Sabe-se que os CPNMs estão fortemente associados com a interação entre a suscetibilidade do hospedeiro e a exposição solar. ${ }^{1}$ Quanto às alterações imunológicas, pouco se sabe, mas pacientes transplantados ou que trataram algum tipo de câncer na infância têm aumento na sua incidência. ${ }^{1}$ Além disso, parece que uma alteração na imunidade celular do hospedeiro é o fator predominante no crescimento de CPNM. ${ }^{1}$

\section{Tipos de pele}

A etnia do paciente faz parte dos fatores de suscetibilidade do hospedeiro ao determinar a incidência do câncer de pele. Indivíduos de cabelo claro, olhos claros, efélides, ruivos, com ancestrais célticos e fototipo de Fitzpatrick I e II (Tabela 3) têm risco elevado de CPNM.,2,6 
Num estudo europeu denominado Helios, foram detectados os seguintes sinais de alerta para aumento no risco de câncer de pele: apresentar tendência a queimaduras e não se bronzear com a exposição solar e história de queimaduras solares na infância.' Isto porque, sabe-se, a melanina tem um efeito protetor na pele por dificultar a penetração dos raios solares.'

\section{Radiação}

Em 1945, foi relatado o primeiro trabalho de pesquisa que documentou a indução de câncer de pele em ratos por raio ultravioleta (UV). Entretanto, somente em 2002, o raio UV foi incluído na lista dos fatores carcinogênicos para o câncer de pele, lançado pelo National Institute of Environmental Heatlh Sciences. ${ }^{2}$ Atualmente, vários estudos já comprovaram que a exposição aos raios UV é a principal causa de câncer de pele. Os raios UV induzem ao câncer de pele por três mecanismos:

(1) dano direto ao DNA, levando à mutação genética;

(2) produção de moléculas ativadas de oxigênio, que resultam no dano ao DNA celular e outras estruturas moleculares; $\mathrm{e}$

(3) bloqueio localizado da imunossupressão anticâncer das defesas naturais do corpo. ${ }^{1}$

Nos casos de CBC, sabe-se que a radiação UV é capaz de induzir mutações genéticas no DNA celular pela modificação dos genes p53 e patch (PTCH1), que são genes supressores da carcinogênese. 'Além disso, gera inflamação na pele com aumento da produção de prostaglandinas que induzem a síntese de ciclooxigenase 2 (COX-2), que também contribui para a gênese do $\mathrm{CBC}$.

Os comprimentos de onda responsáveis pelo câncer de pele estão na faixa do UVB (280-320 $\mathrm{nm}$ ) e do UVA (320-400 nm). ${ }^{1}$ Muito em função disso, regiões e países localizados próximos à linha do Equador, que recebem maior incidência desses raios, apresentam as taxas de prevalência mais altas do mundo. ${ }^{1}$ A Austrália tem a taxa mais alta de $\mathrm{CBC}$ do mundo, com uma incidência de $1 \%$ nas regiões tropicais, já que está incluída nos países próximos à linha do Equador e tem a maioria da sua população com fototipos baixos. ${ }^{3}$

O Brasil também é um país predominantemente de clima tropical, com $92 \%$ do seu vasto território localizado entre a linha do Equador e o trópico de Capricórnio. Ainda é banhado pelo Oceano Atlântico, com uma extensão de praias que chega a mais de sete mil quilômetros, e possui uma das mais ricas redes hidrográficas do mundo. Esses são alguns dos fatores que fazem desse país um lugar propício para o recebimento durante todo o ano de grandes quantidades de radiação solar e para o desenvolvimento de atividades socioeconômicas relacionadas direta ou indiretamente à exposição solar, como a pesca, a agricultura e até mesmo o lazer. Com isso, a

Tabela 3. Classificação dos fototipos de Fitzpatrick.

\begin{tabular}{|l|l|l|}
\hline \multicolumn{1}{|c|}{ Fototipos } & \multicolumn{1}{|c|}{ Descrição } & \multicolumn{1}{c|}{ Sensibilidade ao sol } \\
\hline I-Branca & $\begin{array}{l}\text { Pele muito branca, cabelo em geral ruivo. A pele queima } \\
\text { facilmente e dificilmente se bronzeia. }\end{array}$ & Muito sensível \\
\hline II-Branca & $\begin{array}{l}\text { Pele branca, cabelos loiros e olhos claros. A pele queima facil- } \\
\text { mente e bronzeia moderada e uniformemente. }\end{array}$ & Sensível \\
\hline III-Morena clara & $\begin{array}{l}\text { Pele branca, cabelos castanhos escuros ou pretos. A pele quei- } \\
\text { ma e bronzeia moderada e uniformemente. }\end{array}$ & Normal \\
\hline IV-Morena moderada & $\begin{array}{l}\text { Pele clara ou bege, incluindo pessoas orientais. A pele queima } \\
\text { pouco, bronzeia fácil e moderadamente. }\end{array}$ & Normal \\
\hline V-Morena escura & $\begin{array}{l}\text { Pele parda escura ou marrom médio (pessoas mulatas). } \\
\text { Queima raramente, bronzeia muito e mancha com facilidade. }\end{array}$ & Pouco sensível \\
\hline VI- Negra & $\begin{array}{l}\text { Pele totalmente pigmentada (negra). Queima muito rara- } \\
\text { mente, bronzeia muito e mancha com facilidade. }\end{array}$ & Resistente \\
\hline
\end{tabular}

Fonte: Tabela adaptada do livro Cancer of the Skin. ${ }^{2}$ 
preocupação está no fato de toda a sua população estar constantemente exposta a um dos grandes fatores causadores do câncer de pele. A partir daí, faz-se necessária a educação da população quanto à prevenção da exposição aos raios UV.

\section{Outros fatores}

Alguns tipos de exposição e condições que levam ao aumento no risco de desenvolvimento de CPNM são:

- a exposição aos raios ionizantes (por exemplo a radioterapia), ao arsênico e hidrocarbonetos;

- fototerapia com UVA;

- cicatriz de queimadura;

- úlcera venosa crônica;

- osteomielite crônica;

- imunossupressão (por exemplo os transplantados);

- portadores de diversas dermatoses, como: xeroderma pigmentoso (caracterizado pela inabilidade de reparar o dano ao DNA induzido por UV), síndrome nevoide do carcinoma basocelular (provocada por uma mutação no gene PTCH1) e síndrome de Bazex (genodermatose ligada ao X, caracterizada por atrofodermia folicular, CBC e anidrose localizada);

- histórico pessoal de câncer de pele; e

- fototipo baixo (tipos de pele I e II) ${ }^{1,2}$

\section{Tratamento do CPNM}

Uma vez diagnosticado, o CPNM tem uma variedade de tratamentos disponíveis. Durante essa escolha, diferentes fatores tumorais devem ser considerados: ${ }^{1,2}$

- tamanho;

- localização;

- $\quad$ tipo histopatológico e morfológico;

- natureza (lesão primária ou recorrente); e

- invasão de estruturas.

Também devem ser considerados os fatores referentes ao paciente, como: sua idade, suas comorbidades e sua expectativa quanto à cicatriz e seu aspecto estético. ${ }^{12}$

De acordo com a National Comprehensive Cancer Network (NCCN), o tratamento do CPNM deverá sempre ter como prioridade a cura completa do tumor. ${ }^{2}$ Depois disso, as outras prioridades são: ${ }^{2}$

(1) preservação da pele sã adjacente;

(2) preservação da função da área tratada; e

(3) melhor resultado cosmético possível.

Por fim, a NCCN recomenda que todos os CPNM devam ser biopsiados anteriormente a qualquer procedimento, permitindo a escolha mais apropriada do seu tratamento. ${ }^{2}$ Porém, quando o diagnóstico clínico, a extensão ou o subtipo histológico não foram determinados antes do tratamento ou quando o tratamento não permitiu a avalição de margens, a NCCN recomenda a realização de uma nova biópsia após a cicatrização. ${ }^{2}$

Ainda de acordo com a NCCN, a escolha do tratamento do CPNM também está relacionada com o comportamento biológico do tumor e com a presença de pelo menos um dos riscos de recorrência listados abaixo: ${ }^{2}$

- diâmetro maior que $20 \mathrm{~mm}$ no tronco ou em extremidades;

- diâmetro maior que $10 \mathrm{~mm}$ em cabeça ou pescoço;

- diâmetro maior que 6 mm em genitália, mãos ou pés;

- bordas mal definidas;

- recidiva;

- imunossupressão;

- área previamente tratada com radioterapia;

- tipo histológico; e

- acometimento perineural.

Porém, sabe-se que cada CPNM representa uma escolha única de tratamento e que esta deve ser feita avaliando a melhor relação entre custo e benefício para o paciente. ${ }^{2}$

Num estudo publicado em 2012 no British Journal of Dermatology denominado European Prevention Iniciative for Dermatological Malignancies (Epiderm) foram avaliadas as preferências entre os dermatologistas europeus de técnicas de tratamento para o câncer de pele 
em todos os países da União Europeia. A partir daí, concluiu-se que a cirurgia é o tratamento de escolha com $65,4 \% .{ }^{6}$ Outro dado é que, apesar das vantagens apresentadas pelos tratamentos não cirúrgicos e não ablativos, eles não excederam os métodos ablativos como a crioterapia. ${ }^{9}$

Nesse mesmo estudo, também foi demonstrado que a cirurgia foi a primeira escolha para a abordagem dos dermatologistas dos centros de tratamento dos hospitais universitários, correspondendo a $76,5 \%$ das escolhas de tratamento. ${ }^{6}$ Porém, em pacientes acima de 60 anos e na área da cabeça, os métodos não cirúrgicos são mais utilizados. ${ }^{6}$ Ainda, revela que, apesar da escolha da terapêutica se basear em diversos critérios como os já expostos anteriormente (condições do paciente, tipo e tamanho do tumor, dentre outros), o principal fator determinante na escolha foi a preferência terapêutica do profissional médico. ${ }^{6}$

A partir daí, pode-se pensar que são necessários mais estudos sobre essas novas técnicas não cirúrgicas (imiquimode, TFD, 5-fluoracil), com protocolos mais bem-estabelecidos para que possam fazer parte da rotina de tratamento dos cânceres de pele.

\section{Referências}

1. Noury, Keyvan. Skin Cancer. 1a ed. Mc Gralw Hill (Australia); 2007.

2. Rigel, Darrell S. Cancer of the skin. 2a ed. Elsevier (China); 2011.

3. Instituto Nacional de Câncer. Estimativa 2014: Incidência de Câncer no Brasil. Rio de Janeiro: INCA, 2014.

4. Instituto Nacional de Câncer. Estimativa 2012: Incidência de Câncer no Brasil. Rio de Janeiro: INCA, 2012.

5. Instituto Nacional de Câncer. Estimativa 2010: Incidência de Câncer no Brasil. Rio de Janeiro: INCA, 2010.

6. Ferrandiz L, Ruiz-de-Casas A, Trakatelli M, de Vries E, Ulrich M, Aquilina S, et al. Assessing physicians' preferences on skin cancer treatment in Europe. British Journal of Dermatology. 2012;167(2):29-35. 